\title{
FACILITY LAYOUT REDESIGN FOR EFFICIENCY IMPROVEMENT AND COST REDUCTION
}

\author{
György Kovács ${ }^{1}$, Sebastian Kot ${ }^{2,3}$ \\ ${ }^{I}$ Institute of Logistics, University of Miskolc \\ Miskolc, Hungary \\ ${ }^{2}$ The Management Faculty, Czestochowa University of Technology \\ Czestochowa, Poland \\ ${ }^{3}$ North-West University, Faculty of Economic Sciences and IT \\ South Africa \\ altkovac@uni-miskolc.hu, sebacat@zim.pcz.czest.pl
}

Received: 17 January 2017; accepted: 27 February 2017

\begin{abstract}
In a competitive market the manufacturing companies have to produce cost effective products which can be realized by minimized production cost and higher effectiveness. The effective facility planning can significantly reduce the operational costs of companies. An adequate facility layout can result in the improvement of the performance of the production line. The Facility Layout Problem (FLP) is relating to location of objects (departments, workstations, machines, etc.) on a given site and the material flow between these objects. The goal of this study is to show the reasons, objectives and steps of a layout redesign process. The minimization of the workflow realized on the shop floor is an often applied an objective function during the layout redesign. Material flow efficiency is a commonly used term for the determination of the amount of workflow, which is the multiplication of material flow data and distance data. In this study, this mathematical method for workflow calculation is introduced. The described case study shows how the efficiency and reduced manufacturing cost of a real manufacturing system can be improved by re-layout design, while smaller floor space is needed for the production.
\end{abstract}

MSC 2010: $91 B 32$

Keywords: facility layout, layout redesign, workflow, efficiency improvement

\section{Introduction}

In the growing market globalization, where customer demands are changing continuously, the enterprises have to focus on cost reduction and profitability.

This research study is very important and actual, because the cost reduction and the improvement of productivity are very important goals of all of manufacturing companies [1].

Within production, the resources (raw materials, energies, humans, machines, equipment and other facilities) are always limited. It is very important at the manu- 
facturing companies to produce cost effective products which can be realized by a minimized production cost with higher effectiveness.

The optimal facility layout is an effective tool in cost reduction by enhancing the productivity. Facility layout design involves a systematic physical arrangement of different departments, workstations, machines, equipment, storage areas and common areas in a manufacturing industry [2].

There are two methods for layout improvement. The first is the re-routing of material flow in a given facility that can improve the efficiency of material movement. When re-routing is not efficient, the other more drastic way is the re-layout. In most of cases the re-layout requires more time, effort and is more expensive [3].

The article is original and unique, because besides the description of theoretical background relating to the layout redesign, a practical method was also introduced in a case study.

In this article, a design method was introduced for re-layout of an assembly plant, and confirmed that the re-layout is an effective tool for process improvement, because the value of the analyzed 4 indicators (amount of workflow, total travel distance of goods, space used for assembly, efficiency of Kanban circle) can be improved after the re-layout.

\section{Research goals and methodology}

The definition of facility layout may be given as the arrangement of machinery and flow of materials from one facility to another, which minimizes material handling costs while considering any physical restrictions on such arrangement [4]. Facility layout considers available space, the final product, user safety and facility and convenience of operations [5]. Facility layout concerns with the optimum arrangement of departments with known dimensions in such a way that minimizes materials handling and ensures effective utilization of men, equipment and space [5].

The Facility Layout Problem (FLP) relates to the location of objects (departments, workstations, machines, etc.) on a given site and the material flow between these objects.

The most important reasons of the redesign of facility layouts are the continuously fluctuating customer demands and changing market environment. Changes in the product portfolio, production volume, as well as changes in the manufacturing process and technology can result in bad utilization of space, huge work in progres at the plant, high material handling distances, bottlenecks at workstations, idle time of facilities and workers, etc. [2].

There are lot of theoretical methods for design and optimisation of FLPs [2, 6-8], both for new facility design and for redesign of an existing layout.

Simulation technique is also recommended in the facility planning analysis. Often used softwares in facility planning are PlantSimulation, Flexsim, Witness, Arena, etc. which provide two or three dimensional visualization [9]. These types 
of software are very effective tools for dynamic redesign and comparison of different layout alternatives and scenarios.

The goal of this study is to show the main objectives of the facility layout planning and the general types of production processes and facility layouts. The main objective of the facility re-layout design is to design effective workflow and to improve productivity of machines, material flow and workers. The reasons, objectives and most general steps of a layout redesign process are introduced in a case study. A detailed facility layout redesign was completed within the framework of an $\mathrm{R}+\mathrm{D}$ project. The described case study shows how the efficiency and reduced manufacturing cost of a real life manufacturing system can be improved by relayout design, while smaller floor space is needed for the production.

\section{Facility layout design objectives}

The main objectives of the facility layout planning is to minimize the total distance of goods flow, the material handling cost and the time spent in the manufacturing system. [10]:

An efficient and effective facility layout can cover the following objectives

- to provide optimum space to organize equipment and facilitate movement of goods and to create a safe and comfortable work environment,

- to reduce movement of workers, raw materials, components and equipment,

- to provide plant safety including the safety as its workers,

- to facilitate an extension or change in the layout to accommodate a new product line or technology upgradation,

- to increase production capacity of the organization.

\section{General types of facility layouts}

Production processes can be divided into 5 categories (Fig. 1) in aspect of continuity, product variety and production volume [11-13]:

1. Project production (production is a complex process, low volume, high customization, the sequence of operations is unique to each project/product, fixed position layout).

2. Job-shop production (manufacturing of one or few quantity of products, low volume and high variety of products, general-purpose machines arranged into different departments, each job requires unique technological requirements and machines, requiring highly skilled operators and high inventories).

3. Batch production (shorter production runs, plant and machinery are flexible, manufacturing lead time and cost are lower compared to job-shop production).

4. Mass production (manufacturing of a small variety (mostly only one) and huge volume of products, machines are arranged in a line or product layout, product 
and process sequence are standardized, the cycle time of the production is short, low inventory, balanced production lines, high productivity).

5. Flow/Process production (manufacturing of small variety (mostly only one) and huge volume of products, special purpose machines in a fix sequence, manufacturing cycle time is zero).

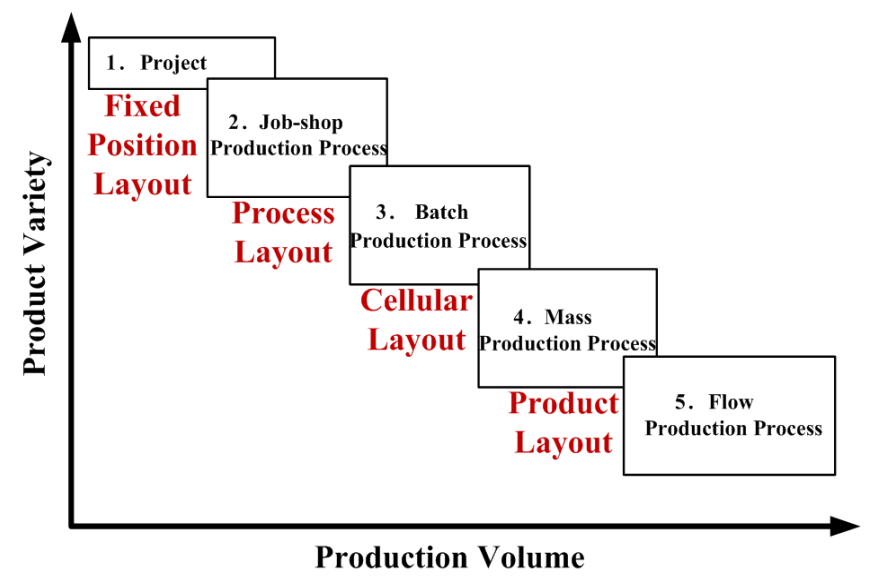

Fig. 1. General types of production processes and facility layouts

There are four main types of facility layout (Fig. 1) which are the following $[4,13]$ :

1. Fixed Position Layout is used in project production used for manufacturing of large and individual products e.g., bridge, ships, etc.

2. Process Layout is typically used in job shop production used for manufacturing of a low volume of customized products,

3. Cellular Layout is suitable for producing a wide variety of final products manufactured in medium volume,

4. Product Layout is used in flow shop production used for manufacturing of a high volume of standard products.

In practice, the most common situation is the mixture of the above-mentioned layout types.

\section{Case study for re-layout design}

The main objective of the facility re-layout design is to design effective workflow and to improve productivity of machines, material flow and workers.

The most general process of layout redesign is the following:

1. at first, the problem has to be defined (e.g. bottlenecks, lack of space, etc.),

2. the defined problem should be analyzed,

3. alternative solutions (e.g. layout variations) should be elaborated, 
4. elaborated alternatives have to be analyzed and evaluated based on key performance indicators,

5. the best layout design has to be selected and

6. finally the preferred solution should be implemented.

In the next part of the article, a case study will be introduced for a layout redesign. The redesign was completed in the frame of an $\mathrm{R}+\mathrm{D}$ project.

\subsection{Problem formulation - actual layout}

Actual layout to be redesign can be seen in Figure 2. The main profile of the analyzed company is manual assembly of mechatronical products. The dimension of the shop floor is $20 \mathrm{~m} \times 12.5 \mathrm{~m}\left(250 \mathrm{~m}^{2}\right)$. The manufacturing process includes 11 workstations. Some of the workstations (No 1, No 2, No 3) are in the fixed position, the others are moveable. The material flow between the workstations is also depicted in Figure 2, the dimension of the material flow is unit load (UL). The component supply of the assembly process is realized based on the Kanban principle. The Kanban circle has 3 stops, where the loading-in and loading-out of components and final products are completed.

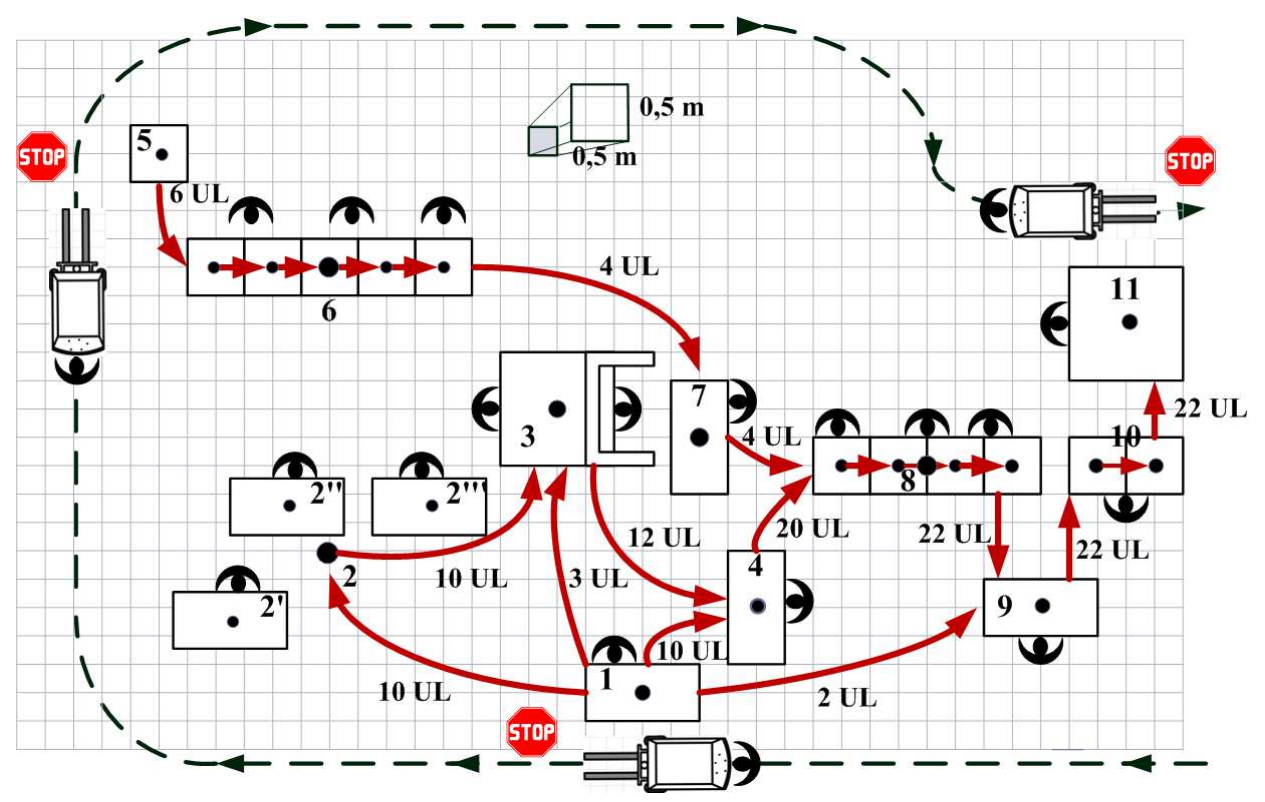

Fig. 2. Actual layout

\section{Reasons for the layout redesign:}

- the company will have a new business (new customer), a new product group has to be assembled,

- the new product type requires new assembly lines,

- the new assembly lines require more space $\left(\sim 70 \mathrm{~m}^{2}\right)$, 
- the area of the actual assembly activity should be reduced by reorganization (re-layout) of the existing workstations,

- free space should be formed on the existing shop floor.

Goals of the layout redesign:

- provide free space for the new business,

- provide an optimum arrangement of workstations and movement of goods on the shop floor,

- reduce movement of raw materials, components, equipment and workers,

- reduce lead times and increase production capacity,

- create a safe and comfortable work environment.

\subsection{Alternative solutions for ideal layout}

Five alternative layouts were designed during the research, but due to the page limit, only the best solution (Fig. 3) will be introduced in details.

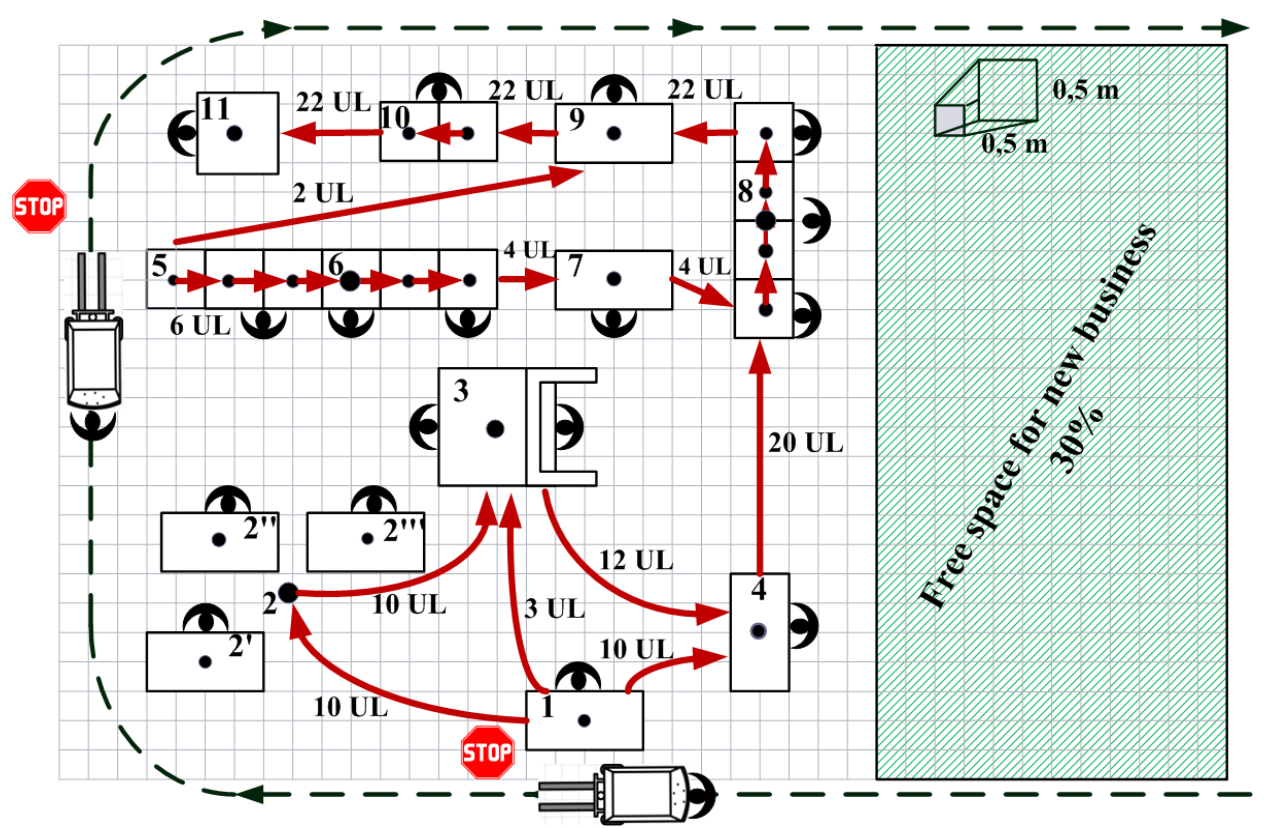

Fig. 3. Ideal new layout

Workstations (No 1, No 2, No 3) are in the fixed position, but the other moveable workstations can be removed arbitrarily. The cellular manufacturing has lot of advantages, so the moveable workstations will be organized into a U-shaped cell.

The amount of the material flow between the workstations is the same as before the re-layout, because the production technology and the number of final products to be produced are the same. 


\subsection{Evaluation of elaborated layout solutions}

To find the optimal solution for a given task, the evaluation and comparison of elaborated layouts have to be realized.

In our case, the basis of the comparison (before/after) is the:

1. amount of the workflow in the whole assembly process,

2. total travel distance of goods in the system,

3. available free space for the new business,

4. number of stops and length of Kanban circles.

(Comparison of the actual layout (Fig. 2) and the redesigned layout (Fig. 3) will be summarized in Table 1 based on the above-mentioned 4 indicators.)

Material flow efficiency is a commonly used term for the determination of the amount of workflow. Material flow efficiency is the multiplication of traffic data and distance data.

\section{Material flow (traffic) matrix:}

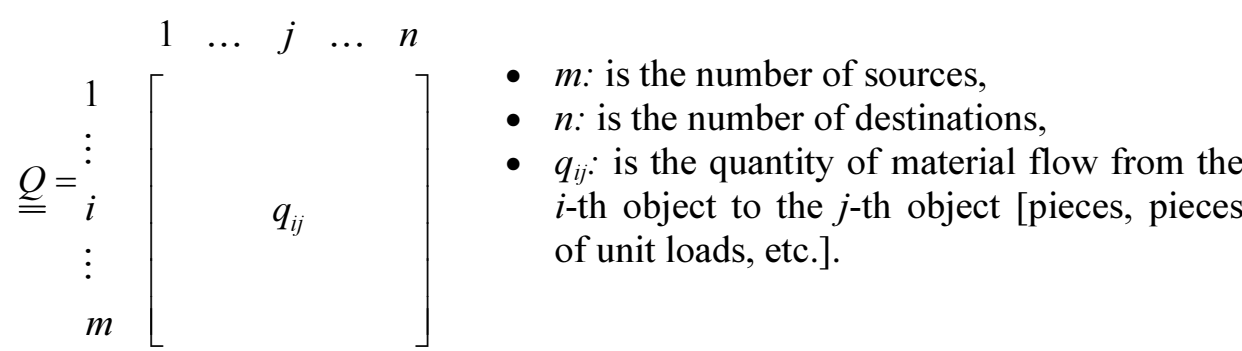

\section{Distance matrix:}

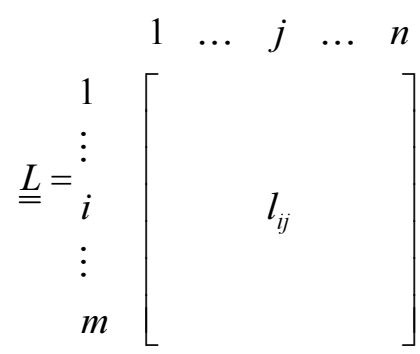

- $m$ : is the number of sources,

- $n$ : is the number of destinations,

- $l_{i j}$ : is the distance between the $i$-th object and $j$-th object [in $\mathrm{m}, \mathrm{cm}$, etc.].

The material flow effectiveness matrix:

Minimization of the material flow efficiency is a very often used improvement aim in practice. Material flow efficiency is the multiplication of material flow quantity data and distance data.

$$
\underline{\underline{W}}=\underline{\underline{Q}} \cdot \underline{\underline{L}}
$$




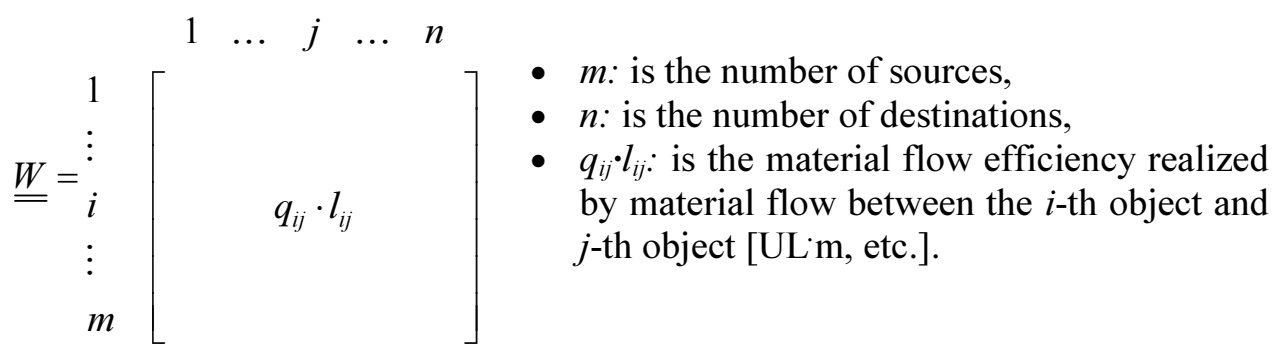

The total material workflow of the system can be obtained by summarizing the elements of columns and rows of the $\underline{\underline{W}}$ matrix. The total material workflow can be reduced by reducing the quantity of material flow $\left(q_{i j}\right)$ or reducing the distance of material flow $\left(l_{i j}\right)$. In our case, the re-arrangement of workstations results in the modification of the material flow distances.

Material flow in case of our case study can be defined by the followings matrix (the matrix is the same for the actual and for the new layout, because the assembly technology is not modified, only the arrangement of the workstations):

$$
\underline{\underline{Q_{\text {Act, New }}}}=\left[\begin{array}{ccccccccccc}
0 & 10 & 3 & 10 & 0 & 0 & 0 & 0 & 2 & 0 & 0 \\
0 & 0 & 10 & 0 & 0 & 0 & 0 & 0 & 0 & 0 & 0 \\
0 & 0 & 0 & 12 & 0 & 0 & 0 & 0 & 0 & 0 & 0 \\
0 & 0 & 0 & 0 & 0 & 0 & 0 & 20 & 0 & 0 & 0 \\
0 & 0 & 0 & 0 & 0 & 6 & 0 & 0 & 0 & 0 & 0 \\
0 & 0 & 0 & 0 & 0 & 0 & 4 & 0 & 0 & 0 & 0 \\
0 & 0 & 0 & 0 & 0 & 0 & 0 & 4 & 0 & 0 & 0 \\
0 & 0 & 0 & 0 & 0 & 0 & 0 & 0 & 22 & 0 & 0 \\
0 & 0 & 0 & 0 & 0 & 0 & 0 & 0 & 0 & 22 & 0 \\
0 & 0 & 0 & 0 & 0 & 0 & 0 & 0 & 0 & 0 & 22 \\
0 & 0 & 0 & 0 & 0 & 0 & 0 & 0 & 0 & 0 & 0
\end{array}\right] \text { [UL] }
$$

The distances of goods between workstations in case of the actual layout can be defined by the following matrix (the distances of workstations are measured between the geometrical centres of objects, the movement is completed along the coordinate axes): 


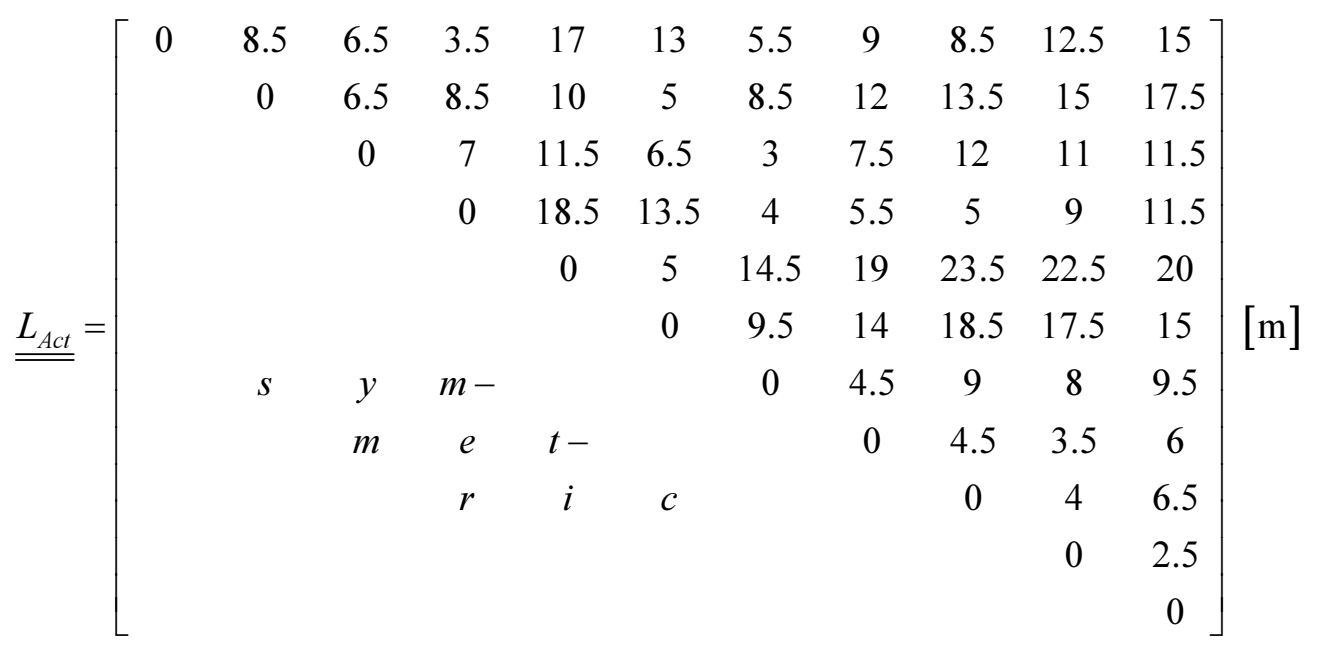

The distances of goods between workstations in case of the redesigned new layout can be defined by the following matrix:

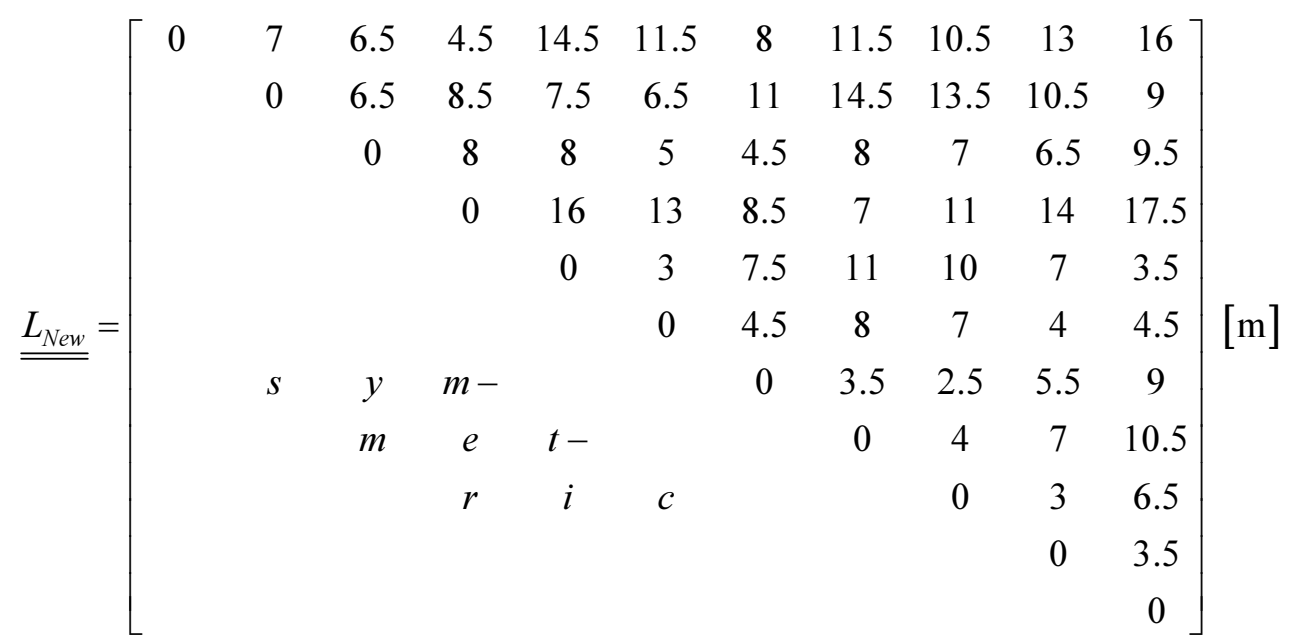

Material flow efficiency $(\underline{\underline{W}})$ is the multiplication of material flow quantity data and distance data (eq. (1)).

The total material workflow of the assembly system can be obtained by summarizing the elements of columns and rows of the $\underline{\underline{W}}$ matrix.

Total material workflow in case of the actual layout is:

$$
W_{\text {Act }}=743.5[\mathrm{UL} \cdot \mathrm{m}]
$$

Total material workflow in case of the new layout is:

$$
W_{\text {New }}=736.5[\mathrm{UL} \cdot \mathrm{m}]
$$


The result of layout redesign can be summarized in table 1 . based on the 4 most important indicators:

Table 1

Result of layout redesign

\begin{tabular}{|l|c|c|c|}
\hline & $\begin{array}{c}\text { Actual layout } \\
\text { Fig. 2 }\end{array}$ & $\begin{array}{c}\text { New layout } \\
\text { Fig. 3 }\end{array}$ & Difference \\
\hline 1. Workflow [UL'm] & 743.5 & 736.5 & $-0.94 \%$ \\
\hline 2. Total travel distance of goods [m] & 152 & 142 & $-6.58 \%$ \\
\hline 3. Space used for assembly [m $\left.{ }^{2}\right]$ & 250 & 175 & $-30 \%$ \\
\hline 4. Stops in the Kanban circle [pieces] & 3 & 2 & $-33.33 \%$ \\
\hline
\end{tabular}

It can be concluded that the goals of the research project were achieved. $75 \mathrm{~m}^{2}$ of free floor space can be provided for the new business, while the movement of raw materials and components was reduced due to the optimal arrangement of workstations. The Kanban component supply has become more efficient because the number of stops was reduced, which can reduce the lead time of this activity. The length and the path of the Kanban circle is the same. Some workstations of the assembly activities can be organized into cellular layout (No 5 - No 11) which has the same additional advantages, e.g. reduced material handling and transit time, reduced setup time, reduced work-in-process inventory, better use of human resources and better scheduling, easier to control.

It can be seen based on Table 1. that the value of all of 4 indicators was improved at the company, so the $\mathrm{R}+\mathrm{D}$ project was absolutely successful.

\section{Conclusions}

This research study is very important and actual, because the cost reduction and the improvement of productivity are very important goals of all of manufacturing companies.

The article is original and unique because, besides the description of theoretical background relating to the layout redesign, a practical method was also introduced in a case study.

Effective facility planning can significantly reduce the operational costs of companies and improve the performance of production lines. The Facility Layout Problem (FLP) relates to the location of objects (departments, workstations, machines, etc.) on a given site and the material flow between these objects. The most important reasons for redesigning facility layouts are the continuously fluctuating customer demands, resulting changes in the product portfolio, production volume, changes in manufacturing process and technology.

The goal of this study was to show the main objectives of the facility layout planning and the general types of production processes and facility layouts. 
The reasons, objectives and most general steps of a layout redesign process were introduced in a case study. In this article, a design method was introduced for the re-layout of an assembly plant, and confirmed that the re-layout is an effective tool for process improvement.

The minimization of workflow realized on the shop floor is an often applied objective function during the layout redesign. In this study, the mathematical method for workflow calculation was introduced $[14,15]$. Material flow efficiency is used for the determination of the amount of total workflow of the manufacturing system. Material flow efficiency $(\underline{\underline{W}}=\underline{\underline{Q}} \cdot \underline{\underline{L}})$ is the multiplication of material flow volumes and distances between the workstations.

In the article, a real plant layout redesign was described. More alternatives were planned for the layout and compared based on 4 indicators (amount of the workflow in the whole assembly process, total travel distance of goods in the system, available free space for the new business and number of stops and length of Kanban circles).

It can be concluded that the value of the analyzed 4 indicators was improved after the re-layout. The re-layout resulted in free space for the new business, optimum arrangement of workstations and movement of goods on the shop floor, reduced movement of goods and reduced lead times and increased production capacity. The described case study showed how the efficiency and reduced manufacturing cost of a real life manufacturing system can be improved by re-layout design, while smaller floor space is needed for the production.

\section{References}

[1] Matalycki M., Kiturko O., Basiewicz N., Application of HM-networks in problems of transport logistics, Scientific Research of the Institute of Mathematics and Computer Science 2010, 9, 2, 153-172.

[2] Naik B.S., Kallurkar S., A literature review on efficient plant layout design, International Journal of Industrial Engineering Research and Development 2016, 7, 2, 43-51.

[3] Zhang M., Batta R., Nagi R., Designing manufacturing facility layouts to mitigate congestion, 2009, http://www.acsu.buffalo.edu/ batta/designing.pdf, downloaded: 02.09.2016.

[4] Khoshnevisan M., Bhattacharya S., Smarandache F., Optimal plant layout design for processfocused systems, https://arxiv.org/ftp/math/papers/0302/0302031.pdf, downloaded: 12.10.2016.

[5] Riyad H., Kamruzzaman R., Subrata T., Increasing productivity through facility layout improvement using systematic layout planning pattern theory, Global Journal of Researches in Engineering: J - General Engineering 2014, 14, 7, 1-7.

[6] Bhowmik R., An approach to the facility layout design optimization, International Journal of Computer Science and Network Security 2008, 8, 4, 212-220.

[7] Ojaghi Y., Khademi A., Yusof N.M., Renani N.G., Syed Helmi S.A., Production layout optimization for small and medium scale food industry, Procedia CIRP 2015, 26, 247-251.

[8] Tompkins J.A., White J.A., Bozer Y.A., Tanchoco J.M.A., Facilities Planning, 4th ed., John Wiley $\&$ Sons Inc., New York 2010. 
[9] Kovács G., Tamás P., Simulation methods in logistics, Memooc on-line course, Institute of Logistics, University of Miskolc, 2015., http://www.memooc.hu/courses/ /coursev1:UniMiskolc+IT.L1.SYMULATIONS.0.E +2015_T1/about

[10] MSG-Management Study Guide, http://www.managementstudyguide.com/facility-layout.htm, downloaded: 18.10.2016.

[11] Kovács G., Tamás P., Introduction and Analysis of Production Processes, textbook, University of Miskolc, Institute of Logistics, 2015.

[12] Ostwald P.F., Muñoz J., Manufacturing Processes and Systems, 9th Edition, 1997.

[13] Korhan O., Facilities planning and design - IENG441, lecture notes, Department of Industrial Engineering, Eastern Mediterranean University, http:/ie302.cankaya.edu.tr/uploads/files/ file/LectureNotes/IENG441\%20Facilities\%20Planning\%20and\%20Design\%20\%20Lecture\%20 Notes.pdf, downloaded: 10.10.2016.

[14] Ladyga M., Lovasova R., The method of balancing the production and consumption model in the case of indivisible, Polish Journal of Management Studies 2015, 11(2), 83-90.

[15] Kovács G., Kot S., New logistics and production trends as the effect of global economy changes, Polish Journal of Management Studies 2016, 14(2), 115-126. 